\title{
APROPRIAÇÃO E PRODUÇÃO DE CONHECIMENTOS NA PRÁTICA DE ENSINO DO PROFESSOR DE EDUCAÇÃO FÍSICA: UM RELATO DE EXPERIÊNCIA*
}

\author{
Rosiris Pereira de Souza CAVAlCANTi * *
}

RESUMO

O presente texto relata as experiências vivenciadas no desenvolvimento do projeto de pesquisa do qual resultou esta monografia de conclusão do curso de especialização em Educação Física Escolar. O projeto teve como objetivo desvelar como os professores de Educação Física lidam com o conhecimento elaborado na escola e de que maneira este profissional apreende as relações estabelecidas em uma matriz de conhecimentos que envolvem educação, cultura e sociedade. Após contextualizar a realidade da Educação Física em Goiânia e também em outras cidades na intenção de vislumbrar o perfil da Educação Física Escolar brasileira, estabelecemos os procedimentos metodológicos, a análise das categorias internas do trabalho, a prática pedagógica, a fonte do conhecimento e a organização do conhecimento. Neste sentido foram realizadas observações e entrevistas com dois professores da Rede Municipal de Ensino de Goiânia. PALAVRAS-CHAVE: Educação Física Escolar - Apropriação e Produção de Conhecimentos.

\section{INTRODUÇÃO}

\begin{abstract}
A forma como os professores de Educação Física lidam com o A conhecimento elaborado na escola, tem desencadeado um grande desafio no campo investigativo, particularmente na tentativa de desvelar de que maneira estes profissionais apreendem as relações estabelecidas em uma matriz de conhecimentos que envolve educação, cultura e sociedade.

\footnotetext{
" Relato extraído das experiências vividas durante o processo de coleta de dados para o projeto de pesquisa que se materializou em trabalho monográfico apresentado como exigência para conclusão do curso de especialização em Educação Física Escolar, sob mesmo título, em junho de 2001, sob orientação do professor Nivaldo Antônio Nogueira David.

** Professora de Educação Física, na FEF/UFG e especialista em Educação Física Escolar pela FEF/UFG
} 
Através da vivência com professores de Educação Física Escolar do Estado e do município de Goiânia e com dados referentes à realidade da Educação Física Escolar, percebemos que os professores apresentavam formas particulares para a compreensão de aspectos amplos da sociedade e das relações diretas e indiretas destes em sua prática de ensino. Foram considerados os vários problemas enfrentados pelo coletivo de professores e pela educação em geral, entre eles a defasagem teórica; a forma fragmentada de organização do pensamento, herança da formação acadêmica; outras deficiências da formação profissional; a falta, dentro das escolas, de um projeto político-pedagógico bem definido; as condições socioeconômicas de nossa sociedade e ainda o contexto atual em que se percebe uma força política no sentido de desmantelamento da educação pública e gratuita em todos os aspectos.

Tentamos identificar o perfil da Educação Física Escolar brasileira com base em alguns trabalhos e estudos na área - dentre eles, a pesquisa realizada pela FEF/UFG em 1995 sobre a realidade da Educação Física na Rede Municipal e Estadual (Goiânia); o estudo de Caparroz (1997); o Coletivo de Autores (1992); o trabalho de Rodrigues (1998 e 2000) e outros -, buscando compreender a realidade e situações que se aproximam ou estabelecem um paralelo com o nosso objeto de estudo. Dentro desta perspectiva tentamos resgatar alguns apontamentos propositivos, resultados de pesquisas realizadas na área de Educação Física Escolar, que se relacionam com o tema deste estudo e com os problemas encontrados no campo de pesquisa. Neles, os autores apresentam propostas que direcionam para a superação dos quadros encontrados. Tentamos também trazer à tona a importância da compreensão, por parte dos professores, sobre a relação dialética que se estabelece entre educação e sociedade, como um dos pilares para a concretização de uma prática pedagógica comprometida com a transformação social. E ainda um levantamento da pesquisa, enquanto princípio educativo (Demo, 2000), como método para apropriação ativa de conhecimentos e também como forma para a superação da dicotomia entre ensino e pesquisa.

Para tentar compreender melhor como se dava a apropriação e produção de conhecimentos pelos professores de Educação Físi-

124 Cavalcanti, R. P. de S. - Apropriação e produção de conhecimentos... 
ca, identificamos três categorias de análise que poderiam nos ajudar:

1. Prática pedagógica: categoria determinante que explica a ação pedagógica planejada ao lidar com o processo de ensino, da aprendizagem e das inter-relações de conhecimentos no ato educativo da escola.

2. Fonte de conhecimento: origem dos conhecimentos (conteúdos de ensino) tratados pelos professores entrevistados. Considera também a formação acadêmica e a experiência profissional dos professores entrevistados.

3. Organização do conhecimento: dimensão da prática pedagógica que está ligada à distribuição do conhecimento. Esta deverá ser compreendida como a forma com que o professor possibilita a assimilação do conhecimento por parte dos alunos.

Estas categorias serviram como instrumentos para a realização da pesquisa e se caracterizam como pontos de investigação para direcionar a pesquisa acerca do objeto de estudo; para tanto levantamos questões (entrevistas com os professores) e direcionamos nosso olhar para estas categorias (observação das aulas).

A escola escolhida para o estudo caracterizava-se por ser uma das 39 selecionadas para implementação do projeto Escola para o Século XXI, no qual, desde 1997, a Secretaria Municipal de Educação desenvolve um processo de construção/reconstrução de uma proposta curricular. Este projeto tem como principal característica os ciclos de formação e as classes de aceleração de aprendizagem (SME/Governo da Cidade de Goiânia, 2001-2004, p. 4).

A escola selecionada possui uma boa estrutura física no geral, porém não havia um espaço adequado para a prática da Educação Física. Mas consideramos um avanço a questão de haver na escola uma sala de aula para a disciplina no período noturno.

A comunidade escolar caracterizava-se por possuir alunos, em sua maioria, de baixo poder aquisitivo; muitos dos alunos do ciclos I e II residem numa creche que existe ao lado da escola.

Os professores foram questionados individualmente se aceitariam participar da pesquisa e se não se importariam com nossa 
presença em suas aulas para a observação. Na posição de observadores não poderíamos deixar muito claro o pretendido pela pesquisa, lembrando a sugestão de Junker, citado por Ludke (1986), para que o participante-observador não ocultasse totalmente suas atividades, mas revelasse somente parte do que pretendia. A preocupação de não deixar totalmente claro o que se pretende visa não provocar muitas alterações no comportamento do grupo observado.

Quanto ao período de permanência da observação em campo, que começou no dia 7 de novembro de 2000 e foi até 31 de março de 2001, obedeceu a uma orientação no sentido de permanecer em campo de pesquisa até que os dados coletados começassem a se repetir. Segundo Ludke (1986), a decisão de permanência ou a extensão do período de observação depende do tipo de problema pesquisado ou do propósito do estudo.

Para analisar a entrevista (aplicação de questionário), utilizamos a análise de conteúdo proposto por Triviños (1992), ou seja, integrar os dados obtidos da realidade histórica (entrevista e observação) com dados bibliográficos previamente consultados.

Referimo-nos às professoras da escola pesquisada, não pelos seus nomes e sim como professoras do matutino (M) e do noturno (N). Primeiro para diferenciá-las e segundo para preservar o anonimato das participantes. Com cada uma das professoras foi realizada uma entrevista, posterior ao momento da observação das aulas, na intenção de manter o clima da entrevista menos formal e mais descontraído, além de poder captar o máximo de veracidade nas informações.

A entrevista teve como direção os três eixos norteadores do estudo: prática pedagógica, fonte do conhecimento e organização dos saberes. Procuramos questionar de que forma os professores se apropriam do conhecimento da área e de que forma organizam estes conhecimentos, para então descobrirmos de que forma produzem (ou reproduzem) conhecimentos em sua prática educativa. Buscou-se também, através do contato com os professores, saber um pouco de sua vida escolar, acadêmica e profissional. Borges (1998), através de seu estudo sobre a construção dos saberes do professor de Educação Física, reforça o valor das experiências vi- 
vidas pelos professores em suas histórias de vida, além da formação acadêmica e profissional. Neste sentido, nos contatos com os professores, foram focalizados temas sobre a trajetória de vida de cada um deles, com o objetivo de identificar o que diferenciava a prática dos docentes pesquisados. Questionamos, por exemplo, elementos relevantes na história da formação profissional de cada um; dados sobre sua formação continuada, como cursos, congressos, palestras, atualizações, participação em algum movimento social, partido, associação etc., onde trabalharam antes, quantos anos de magistério, etc.

As observações tiveram como foco as aulas de Educação Física, tentando direcionar nosso olhar para as questões afetas somente aos temas propostos ao estudo de caso, que foram as formas de apropriação e produção de conhecimentos na prática pedagógica e, em especial, na organização do trabalho pedagógico.

A professora do matutino $(\mathrm{M})$ e a do noturno $(\mathrm{N})$ passaram por experiências parecidas, no que diz respeito à Educação Física, vivenciadas por elas em sua fase de formação escolar. Ambas foram atletas e viveram momentos em que a Educação Física estava altamente determinada pelo esporte de alto rendimento (paradigma da aptidão física) na segunda metade da década de 1960. Tiveram a mesma formação acadêmica, formando-se na segunda metade da década de 1970, mais precisamente em 1975, pelo mesmo centro formador, a Escola Superior de Educação Física de Goiás, hoje integrada à Universidade Estadual de Goiás. Estudaram dentro da mesma grade curricular e possuem posicionamento diferenciado para esta formação. A professora do matutino afirmou, por exemplo, fazer uso das disciplinas voltadas para a didática e a metodologia, além de conhecimentos adquiridos na disciplina de Psicologia. Já a professora do noturno faz uma crítica severa ao currículo ao qual foi submetida em sua formação inicial. Disse utilizar muito pouco dos conhecimentos adquiridos na Esefego, valorizando, em demasia, sua formação em nível de $1^{\circ}$ e $2^{\circ}$ graus e suas experiências vividas na área de Educação Física, no Paraná, na década de 1960.

A professora do noturno $(\mathrm{N})$ demonstrou mais preocupação do que a do matutino (M) com a questão de sua formação continuada, apesar de que ambas estão quase se aposentando. 
Considerando esta aproximação com a formação profissional inicial das duas professoras e ainda os dados obtidos na pesquisa (entrevista e observações), assim como o que dizem os autores que estão centralizando suas áreas de conhecimento neste tema, pudemos perceber de forma clara que as professoras, salvo algumas diferenças, estão se apropriando dos conhecimentos mais relacionados com o cotidiano escolar, desconsiderando sua formação acadêmica. Valorizam apenas os saberes da experiência de cada uma em sua atuação profissional, por anos, na Educação Física escolar.

Este dado nos levou a pensar que estas professoras estão aquém dos conhecimentos produzidos na área, dos debates atuais e dos conhecimentos que partiram da própria prática pedagógica. Demonstram estar conscientes das mudanças ocorridas na área, mais pela via dos PCNs e revistas, como a Nova Escola, do que por estudos sistemáticos e leitura atual da área.

Parecem desconhecer as críticas feitas aos PCNs no tocante à Educação Física e se utilizam do discurso oficial destes para defender sua prática pedagógica, alegando estar de acordo com o proposto para a escola pela Secretaria Municipal de Ensino.

Os professores utilizam-se dos referenciais PCNs-Educação Física sem fazer uma leitura crítica de suas fundamentações teóricas, desconsiderando tanto as contradições contidas no documento quanto as encontradas em sua prática.

Considerando as críticas aos PCNs e percebendo sua efetivação dentro da escola pesquisada, pelo menos no que diz respeito aos aspectos metodológicos e discursivos, lembramos o que vários autores afirmam: os PCNs vêm a reboque dentro dos ajustes estruturais neoliberais, buscando reproduzir, via implementação de políticas públicas destinadas à Educação, os interesses da classe dominante.

A escola hoje representa, apesar de não se reduzir a isto, um campo privilegiado para a reprodução da forma de manutenção dos interesses dominantes. Dentro da escola esta contradição mostra-se em outro sentido, aponta para o local onde se procura equalização de oportunidades. Todavia, entendemos que os professores precisam se reconhecer como atores sociais que desenca-

128 Cavalcanti, R. P. de S. - Apropriação e produção de conhecimentos... 
deiam as mudanças de concepção de sociedade e as formas de relacionamento com a realidade social em que estão inseridos.

A professora (M) demonstrou apropriar-se dos conhecimentos da área de acordo com a concepção ou representação que possui sobre sua função dentro da escola, quando valorizou a disciplina Psicologia. Alegou que, dentro da escola, cumpria funções como mãe e psicóloga, e ainda demonstrou interesse em estudar Assistência Social para dar conta dos problemas enfrentados pelos professores. Denota uma falta de clareza sobre sua função enquanto educadora, sobre a forma como se relacionam os problemas sociais e educacionais dentro da escola. Este posicionamento, decorrente de um tipo de senso comum, revela a crença na idéia de que o domínio de uma disciplina a mais - como, no caso, a Psicologia poderia resolver ou amenizar alguns problemas enfrentados pelos alunos na escola.

Podemos dizer que esta professora somente reproduz os conhecimentos apreendidos no cotidiano de sua experiência em sua prática educativa, enquanto a professora $(\mathrm{N})$ busca uma reflexão um pouco mais ampliada dos processos sociais, considera a realidade social de seus alunos e mostra-se preocupada em direcionar sua prática educativa para este caminho. Esta professora também demonstra possuir uma prática diferenciada no que diz respeito à seleção de seus conteúdos de ensino, buscando autores críticos e trazendo para a sala de aula a discussão sobre os objetivos da Educação Física para o curso noturno. Contextualiza inclusive a questão da inadequação da formação técnica esportivizada para seus alunos e parece estar consciente de que suas ações apontam para outro sentido que não esteja a reboque do paradigma da aptidão física.

Considerar as contradições encontradas entre o referencial teórico da professora $(\mathrm{N})$ revela a superficialidade com que alguns professores vêm tratando seus conteúdos, pois, apesar de buscarem o hábito da leitura e da reflexão, se apropriam dos conhecimentos de forma superficial, não buscam um aprofundamento nos estudos que dizem respeito à sua profissão.

Ainda sobre apropriação de conhecimentos, pudemos observar que há uma predominância deste processo no tocante aos conhecimentos que circulam no meio escolar, talvez indicando uma 
implementação ideológica de política públicas em na forma de discurso dentro da escola.

As diferenças entre as professoras nos levam a considerar os apontamentos de Souza Júnior, sobre as alternâncias ou continuum entre dois pólos nos quais se encontram os professores pesquisados pelo autor. No nosso caso, este continuum ocorre somente com a professora do noturno, ora demonstrando conceber a Educação Física como um fazer reflexivo, ora entrando em contradição que se percebe a partir da identificação dos objetivos de sua prática, trazendo à tona outras finalidades que não coincidem com a prática refletida pela própria professora.

Um ponto a ser levantado a partir deste estudo é a pesquisa enquanto princípio educativo e forma de apropriação ativa de conhecimento pelos professores (Demo, 2000). Esta proposta vislumbra esta possibilidade, dentro da escola básica, como meio de produção de conhecimento, além de possibilitar a superação da condição do professor como mero transmissor de conhecimento, viabilizando através da pesquisa que este detenha os meios e os produtos do processo de apropriação do conhecimento.

Através da pesquisa, o professor poderia se apropriar de conhecimentos que o levariam a compreender as determinações sociais, econômicas e culturais. Uma vez conhecendo-as, ele poderia intervir nesta realidade de forma mais autônoma e crítica, sem conceber a educação como um campo afastado da realidade, mas como um elemento dela integrante. $\mathrm{O}$ professor não só recebe determinações, mas também determina ações interventivas no sentido de pensar uma realidade diferente, que busca a transformação social. Assim, ele deve ter clareza sobre suas concepções de homem, de sociedade e da educação que pretende implementar, bem como sobre o método adequado para isto.

A pesquisa possibilita a compreensão da relação entre teoria e prática, em que uma não nega a outra e ambas não se sobrepõem, mas relacionam-se dialeticamente. Com este instrumento podemos vislumbrar a possibilidade de uma superação do quadro diagnosticado nas realidades encontradas, superando inclusive a atuação pedagógica que se baseia em uma atitude de reprodução e simples transmissão de conhecimentos adquiridos em formações iniciais. 
Transformar esse discurso em prática é o grande desafio dos centros formadores de saber. As universidades que se sentem compromissadas com a maioria desprestigiada dentro do contexto social precisam mostrar seu papel social no contexto atual, que exige respostas concretas para possibilitar as mudanças necessárias.

Dentro desta linha de pensamento, busca-se uma formação inicial e continuada que traga um avanço dentro das concepções cristalizadas dos professores de Educação Física. Que ofereça à prática pedagógica a contribuição da ciência em prol de uma conscientização sobre as relações que se estabelecem na escola, direcionando ações de intervenção social conscientes, pedagógica e politicamente competentes.

\section{CONSIDERAÇÕES FINAIS}

Com base nos dados analisados nesta pesquisa, pudemos reafirmar que os professores demonstram, em suas práticas pedagógicas, possuir uma forma particular de organização de seus conhecimentos. Estes estão vinculados a vários fatores, entre eles, sua formação acadêmica, sua formação profissional, suas experiências, suas representações e implementações de políticas públicas para a educação, além de outras determinações socioeconômicas. Estas direcionam sua prática pedagógica no sentido da reprodução de algumas ações que contribuem historicamente para a manutenção dos interesses da classe dominante. Neste estudo, porém, defendemos a possibilidade de apropriação e produção de conhecimentos pelo viés da pesquisa, enquanto meio ativo para este processo em todos os níveis escolares. Ampliando a capacidade de compreensão dos professores quanto à relação entre educação e sociedade, acreditamos que a escola ainda se tornará um espaço vital para a construção de um projeto contra-hegemônico de sociedade.

\section{ABSTRACT}

The present text depicts the experiences of the development of the research project which resulted in the monograph for the conclusion of the course of Specialization in Physical Education Programs at Schools under the same title. The purpose of this study is to unveil the way teachers of Physical Education deal with the elaborated 
knowledge at schools and how these professionals apprehend the relations established by a matrix of knowledge which involves education, culture and society. First, the reality of Physical Education in Goiânia and in other cities, as well, was contextualized in an attempt to discern the profile of the Brazilian Physical Education at Schools. Then, methodological procedures and the analysis of the inner categories of the study, such as the pedagogical practice, the source and the organization of the knowledge were established. For that reason, there were made observations and interviews with two teachers from the Municipal School of Education of Goiânia.

KEYWORDS: Physical Education School - Knowledge Appropriation and Production.

\section{REFERÊNCIAS}

BARTHOLO, M. F. A construção do conhecimento e o projeto político-pedagógico da Educação Física. Pensar a Prática, p. 53-64, jul/jun. 1999-2000.

BORGES, C. M. F. O professor de Educação Física e a construção do saber. Campinas, SP: Papirus, 1998. (Coleção Magistério: formação e trabalho pedagógico).

CAPARROZ, F. E. Entre a Educação Física da escola e a Educação Física na escola: a Educação Física como componente curricular. Vitória: UFES, Centro de Educação Física e Desportos, 1997. (Coleção Gnosis, 10).

CAVALCANTI, R. P. S. Os intelectuais e a Educação Física. Goiânia, 1996. Monografia de Graduação FEF/UFG.

COLETIVO DE AUTORES. Metodologia do ensino da Educação Física. São Paulo: Cortez, 1992.

DEMO, P. Pesquisa: princípio científico e educativo. 7. ed. São Paulo: Cortez, 2000.

FONSECA, M. O Banco Mundial e a Educação: reflexões sobre o caso Brasileiro. In: GENTILLI, Pablo. (Org.). Pedagogia da exclusão: crítica ao neoliberalismo em educação. Petrópolis, RJ: Vozes, 1995. (Coleção Estudos Culturais em Educação).

KUNZ, Elenor. Esclarecimento e emancipação: pressupostos de uma teoria educacional crítica para Educação Física. Memórias do Congresso Mundial de Educação Física. Rio de Janeiro: Universidade Gama Filho, 1997.

132 Cavalcanti, R. P. de S. - Apropriação e produção de conhecimentos... 
LUDKE, M; ANDRÉ, M. E. D. A. Pesquisa em educação: abordagens qualitativas. São Paulo: EPU, 1986. (Temas Básicos de Educação e Ensino).

PALAFOX, G. H. M. Planejamento coletivo do trabalho pedagógico. NEPEC/UFU, 1997. Mimeografado.

PENIN, S. T. S. A professora e a construção do conhecimento sobre o ensino. Caderno de Pesquisa, São Paulo, n. 92, p. 5-15, fev. 1995.

RODRIGUES, A. T. Educação Física escolar: a cidadania negada. Monografia de conclusão de licenciatura em Educação Física/FEF/ UFG, Goiânia, 1995.

Prática pedagógica e representações sociais sobre a Educação Física escolar: origens, significados, limites e possibilidades. Monografia de Pós-graduação/Especialização em Educação Física Escolar/ FEF/UFG. Goiânia, 1998.

Gênese e sentidos dos parâmetros curriculares nacionais e seus desdobramentos para a Educação Física escolar brasileira. 2001. Dissertação (Mestrado) Faculdade de Educação/UFG, Goiânia.

SEVERINO, A. J. Metodologia do trabalho científico: diretrizes para o trabalho didático-científico na Universidade. 7. ed. São Paulo: Cortez: Autores Associados, 1982. (Coleção Educação Contemporânea, Série Metodologia e Crítica da Ciência).

SOUZA JÚNIOR, M. O saber e o fazer pedagógicos. A Educação Física como componente curricular? ... isso é história! Recife: EDUPE, 1999.

TRIVIÑOS, A. N. S. Introdução à pesquisa em ciências sociais: a pesquisa qualitativa em educação. São Paulo: Atlas, 1987. 
